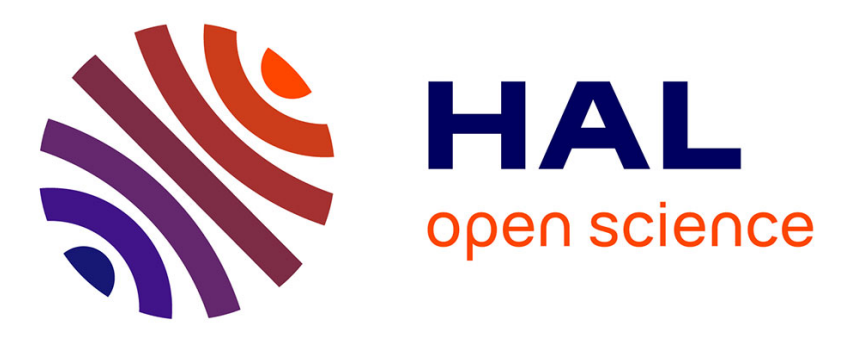

\title{
Mechanical Alterations to Repeated Treadmill Sprints in Normobaric Hypoxia
}

\author{
Franck Brocherie, Grégoire P. Millet, Jean-Benoît Morin, Olivier Girard
}

\section{To cite this version:}

Franck Brocherie, Grégoire P. Millet, Jean-Benoît Morin, Olivier Girard. Mechanical Alterations to Repeated Treadmill Sprints in Normobaric Hypoxia. Medicine and Science in Sports and Exercise, 2016, 48 (8), pp.1570-1579. 10.1249/MSS.0000000000000937 . hal-01628542

\section{HAL Id: hal-01628542 https://hal-insep.archives-ouvertes.fr/hal-01628542}

Submitted on 3 Nov 2017

HAL is a multi-disciplinary open access archive for the deposit and dissemination of scientific research documents, whether they are published or not. The documents may come from teaching and research institutions in France or abroad, or from public or private research centers.
L'archive ouverte pluridisciplinaire HAL, est destinée au dépôt et à la diffusion de documents scientifiques de niveau recherche, publiés ou non, émanant des établissements d'enseignement et de recherche français ou étrangers, des laboratoires publics ou privés. 


\title{
Mechanical Alterations to Repeated Treadmill Sprints in Normobaric Hypoxia
}

\author{
FRANCK BROCHERIE ${ }^{1,2}$, GRÉGOIRE P. MILLET ${ }^{1,2}$, JEAN-BENOIT MORIN $^{3}$, and OLIVIER GIRARD ${ }^{1,2,4}$ \\ ${ }^{1}$ ISSUL, Institute of Sports Sciences, University of Lausanne, Lausanne, SWITZERLAND; ${ }^{2}$ Faculty of Biology and Medicine, \\ Department of Physiology, University of Lausanne, Lausanne, SWITZERLAND; ${ }^{3}$ Laboratory of Human Motricity, Education \\ Sport and Health, University of Nice Sophia Antipolis, Nice, FRANCE; ${ }^{4}$ Aspetar Orthopaedic and Sports Medicine Hospital, \\ Athlete Health and Performance Research Centre, Doha, QATAR
}

\begin{abstract}
BROCHERIE, F., G. P. MILLET, J.-B. MORIN, and O. GIRARD. Mechanical Alterations to Repeated Treadmill Sprints in Normobaric Hypoxia. Med. Sci. Sports Exerc., Vol. 48, No. 8, pp. 1570-1579, 2016. Purpose: Compelling evidence suggests larger performance decrements during hypoxic versus normoxic repeated sprinting. Yet the underlying mechanical alterations have not been thoroughly investigated. Therefore, we examined the effects of different levels of normobaric hypoxia on running mechanical performance during repeated treadmill sprinting. Methods: Thirteen team sport athletes performed eight 5 -s sprints with $25 \mathrm{~s}$ of passive recovery on an instrumented treadmill in either normoxia near sea level $\left(\mathrm{SL} ; \mathrm{FiO}_{2}=20.9 \%\right)$, moderate normobaric hypoxia $\left(\mathrm{MH} ; \mathrm{FiO}_{2}=16.8 \%\right.$; corresponding to $\sim 1800 \mathrm{~m}$ altitude), or severe normobaric hypoxia ( $\mathrm{SH} ; \mathrm{FiO}_{2}=13.3 \% ; \sim 3600 \mathrm{~m}$ ). Results: Net power output in the horizontal direction did not differ $(P>0.05)$ between conditions for the first sprint (mean \pm SD, pooled values: $\left.13.09 \pm 1.97 \mathrm{~W} \cdot \mathrm{kg}^{-1}\right) \mathrm{but}$ was lower for the eight sprints in SH compared with SL $(-7.3 \% \pm 5.5 \%, P<0.001)$ and MH $(-7.1 \% \pm 5.9 \%, P<0.01)$, with no difference between SL and MH $(+0.1 \% \pm 8.0 \%, P=1.00)$. Sprint decrement score was similar between conditions (pooled values: $-11.4 \% \pm 7.9 \%, P=0.49)$. Mean vertical, horizontal, and resultant ground reaction forces decreased $(P<0.001)$ from the first to the last repetition in all conditions (pooled values: $-2.4 \% \pm 1.9 \%,-8.6 \% \pm 6.5 \%$, and $-2.4 \% \pm 1.9 \%$ ). This was further accompanied by larger kinematic (mainly contact time: $+4.0 \% \pm 2.9 \%, P<0.001$, and $+3.3 \% \pm 3.6 \%, P<0.05$, respectively; stride frequency: $-2.3 \% \pm 2.0 \%$, $P<0.01$, and $-2.3 \% \pm 2.8 \%, P<0.05$, respectively) and spring-mass characteristics (mainly vertical stiffness: $-6.0 \% \pm 3.9 \%$ and $-5.1 \% \pm 5.7 \%$, respectively, $P<0.01$ ) fatigue-induced changes in SH compared with SL and MH. Conclusion: In SH, impairments in repeated sprint ability and in associated kinetics/kinematics and spring-mass characteristics exceed those observed near SL and in MH (i.e., no or minimal difference). Specifically, SH accentuates the repeated sprint ability fatigue-related inability to effectively apply forward-oriented ground reaction force and to maintain vertical stiffness and stride frequency. Key Words: SIMULATED ALTITUDE, SPRINTING MECHANICS, REPEATED SPRINT ABILITY, FATIGUE, TEAM SPORTS
\end{abstract}

$\mathrm{D}$ espite distinct skills, tactics, and movement patterns, team sports are characterized by alternating high-intensity actions (i.e., accelerated runs with frequent directional changes, jumps, and kicks) with incomplete recoveries. During the most intense periods of the game or toward match end, team sport athletes experience fatigue as manifested by temporary reductions in high-velocity running and especially peak/mean sprint distances (19), which are both likely to indirectly influence the game outcome (13). The reduction in partial pressure of oxygen $\left(\mathrm{PO}_{2}\right)$ (as seen from moderate-to-high altitudes, hypoxia) is known to lead to premature/larger fatigue during games. For instance, playing

\footnotetext{
Address for correspondence: Grégoire P. Millet, Ph.D., ISSUL, University of Lausanne, Building Geopolis, Campus Dorigny, CH-1015, Lausanne, Switzerland; E-mail: gregoire.millet@unil.ch.

Submitted for publication November 2015.

Accepted for publication March 2016.

0195-9131/16/4808-1570/0

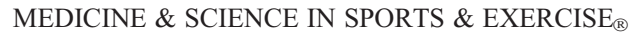

Copyright $(C) 2016$ by the American College of Sports Medicine

DOI: $10.1249 / \mathrm{MSS} .0000000000000937$
}

soccer at altitude $\left(>1500 \mathrm{~m}\right.$; inspired fraction of $\mathrm{O}_{2}, \mathrm{FiO}_{2}<$ $17 \%$ ) detrimentally affects the total distance covered (40), the completion of high-intensity efforts, and the ensuing recovery (14). However, sprint-related measures are highly variable because of match-specific factors (tactics, opposition) and environmental conditions (reduction in air density) (15). Caution is therefore needed when inferring the potential mechanisms underpinning the aforementioned altitudemediated decrements on football performance.

Repeated sprint ability (RSA) tests conducted in the laboratory offer more controlled conditions to shed light on the potential factors compromising fatigue resistance. Previous studies, mainly completed on a cycle ergometer and involving athletes of various training backgrounds, have consistently indicated that normobaric hypoxia $\left(\mathrm{FiO}_{2}\right.$ ranging from $14 \%$ to $16 \%$ ) does not influence single sprint performance but induces earlier and larger decrement in repeated sprint performance compared with sea level (SL) conditions $(2-4,19)$. It is generally accepted that sprints repetition in hypoxia versus normoxia elevates HR (5), minute ventilation (5), $\mathrm{O}_{2}$ debt $(2,5)$, muscle deoxygenation level (3-5), and growth hormone response (28) and lowers surface electromyogram of 
active musculature $(4,5)$. The more recent studies addressing the effects of hypoxia on RSA have specifically tested team sport athletes on nonmotorized treadmills, which favorably increase the validity of their findings. In one of these studies, highly trained team sport athletes were able to match SL performance in hypoxic conditions $\left(\mathrm{FiO}_{2}=14 \%\right)$ during ten 6-s treadmill running sprints separated by $24 \mathrm{~s}$ of passive rest (38). Other RSA treadmill studies comparing graded levels of $\mathrm{FiO}_{2}$ reported that the decrements in RSA with increased hypoxia severity may not follow a monotonic (i.e., linear) pattern $(5,23)$. This was notably demonstrated by Goods et al. (23), who showed using a multiple sets paradigm (i.e., three sets of $9 \times 4$-s treadmill sprints) that peak power output was only further reduced (third set) at $\mathrm{FiO}_{2} \sim 12 \%$ versus $\sim 21 \%$ but not at $\mathrm{FiO}_{2} 14 \%-16 \%$.

In the few available biomechanical studies that have been conducted near SL, specific impairments in sprinting mechanics (i.e., increase in contact time $\left[t_{c}\right]$ and swing time $\left[t_{\text {swing }}\right]$, reductions in vertical stiffness $\left[K_{\text {vert }}\right]$, and stride frequency $\left[S_{\mathrm{F}}\right]$ ) have been connected with progressively slower sprint times/running velocities during overground repeated sprints (i.e., $6 \times 20 \mathrm{~m}-20 \mathrm{~s}$ of passive recovery in U19 footballers [21], $6 \times 35 \mathrm{~m}-10 \mathrm{~s}$ of passive recovery in elite footballers [7], or $12 \times 40 \mathrm{~m}-30 \mathrm{~s}$ of passive recovery in team and racquet sports athletes [20]). Collectively, these findings show that the ability to tolerate ground impact/ stretch loads decreases as fatigue develops with sprint repetitions. Recently, we used a "recovery of performance approach" where hypoxia severity of an initial set of repeated sprints was manipulated and observed that hypoxia had no residual effect during a subsequent set performed in normoxia (18). Under this later study frame, only three out of eight repetitions (i.e., sprints 1,4 , and 8 ) were investigated during the initial set of sprints. Consequently, the time course of changes in sprint mechanical performance could not be accurately described. Hence, the decay in performance during RSA protocols is not linear because fatigability is generally larger during the first versus the last sprint repetitions, as peripheral disturbances are almost immediate and neural factors also contribute to impaired performance during the early stages of such exercise $(19,22)$.

Motorized instrumented treadmills now allow valid (35) and reliable (17) continuous (step-by-step) measurement of instantaneous horizontal and vertical components of the resultant (total) ground reaction force (GRF) during maximal sprints (including the typical acceleration phase) similar to team sport scenarios. A unique feature of this device is to allow the computation of the ratio of support-averaged net horizontal to total force (RF), which gives an indication of the way athletes apply forces onto the ground (technical ability), independently from the amount of total force applied (physical capability) (34). In the only available treadmill studies thoroughly describing changes in sprinting kinetics over repeated sprints, a significant decrease in force production capacity, particularly in the ability to apply it horizontally (i.e., approximately twofold larger reduction than vertical and total forces) has been observed (16,36). As sprint bouts and series were repeated, the technical ability to apply force effectively against the ground was altered and led to shorter and less effective acceleration phase (36). In the previously mentioned studies, however, these observations were restricted to normoxic conditions. It is likely (yet unknown) that increasing hypoxia severity above moderate levels (severe hypoxia $[\mathrm{SH}]$ ) leads to premature and excessive fatigue and is associated with less efficient stride mechanics. Preventing excessive fatigue-induced changes resulting from the additional load imposed by the hypoxic stress during training routines (repeated sprints in hypoxia [6]) or competition would help to improve athletic performance.

The aim of this study was therefore to comprehensively examine performance changes and accompanying running mechanical alterations over a series of treadmill sprints under differing levels of acute normobaric hypoxia severity compared with SL. We hypothesized that the deterioration of RSA and associated alterations in kinetics/kinematics and spring-mass characteristics would be more impaired under SH compared with SL and moderate hypoxia $(\mathrm{MH})$ conditions (i.e., no or minimal difference).

\section{METHODS}

Subjects. Thirteen male volunteers (mean \pm SD age, $31.2 \pm 4.8 \mathrm{yr}$; stature, $178.4 \pm 6.6 \mathrm{~cm}$; body mass, $74.3 \pm$ $8.2 \mathrm{~kg})$ who were recreationally active $\left(4.5 \pm 2.5 \mathrm{~h} \cdot \mathrm{wk}^{-1}\right)$ in intermittent sports (i.e., football, futsal, tennis, and squash) took part in the study. The sample size was estimated from alterations in ground reaction forces as measured during a previous RSA treadmill test (36), requiring $\geq 12$ subjects for a two-way repeated-measures ANOVA with three conditions ( $(=0.85, \alpha=0.05)$. All subjects were lowlanders, with no recent exposition/acclimatization to altitude and free of musculoskeletal pain or injuries. In the 6 months preceding the study, their training included activity-specific (i.e., technical and tactical skills), aerobic (i.e., continuous and intermittent), and anaerobic (i.e., strength, sprints, and change of direction) exercises. Although subjects' training content largely focused on accelerated runs, their sprinting skills are deemed to be "moderate" compared with "elite" (i.e., national to international level) sprinters (41) and/or footballers (7). They were requested to report to the laboratory in a rested and hydrated state, at least $3 \mathrm{~h}$ postprandial and having avoided strenuous exercise in the preceding $48 \mathrm{~h}$. They were also asked to refrain from caffeine for $12 \mathrm{~h}$ and alcohol for $24 \mathrm{~h}$ before each visit. Written informed consent was obtained from participants, and the study was approved by the Shafallah Medical Genetics Center ethics committee and conducted according to the Declaration of Helsinki.

Experimental design. Approximately 1 wk before testing, subjects undertook a complete preliminary session where they performed short $(<5 \mathrm{~s})$ "familiarization" treadmill sprints at increasing intensities while wearing a facemask for habituation (i.e., with the hypoxic system turned off), with full 
recovery and until being comfortable with the running technique required (which generally required $7-10$ trials). Then they performed three maximal 5-s single sprints, separated by $2 \mathrm{~min}$ of passive recovery, and after $5 \mathrm{~min}$ of rest, the RSA test (see RSA section) in full. All of them satisfied the criteria of having a coefficient of variation $<2.2 \%$ for distance covered across three successive trials (17). Strong verbal encouragement was given during all maximal efforts, with no feedback provided, except for the time remaining during recoveries (i.e., $10 \mathrm{~s}, 5 \mathrm{~s}$, and "3-2-1" s countdown before each sprint). In addition, subjects were reminded during each recovery period that the subjective awareness of effort expended during the next sprint effort must be maximal.

Subjects reported to the laboratory on three different occasions at least 3-4 d apart to complete an experimental session ( $\sim 45 \mathrm{~min}$ from the beginning of the warm-up until the end of the RSA test). The study was designed as a randomized double-blind fashion protocol in which subjects and investigators (except one) were blinded toward the environmental conditions. The efficacy of blinding procedure was evaluated after each experimental session by questionnaires in which subjects were asked whether they believed they were exercising in $\mathrm{SL}, \mathrm{MH}$, or $\mathrm{SH}$. Upon arrival at the laboratory (well ventilated at a constant temperature of $\sim 25^{\circ} \mathrm{C}$ and $\sim 40 \%$ relative humidity), subjects were instrumented for physiological measurements (see Physiological responses section). A normoxic standardized warm-up lasting $\sim 15 \mathrm{~min}$ (5 min of running at $10 \mathrm{~km} \cdot \mathrm{h}^{-1}, 10 \mathrm{~min}$ of sprint-specific athletic drills; i.e., $3 \times$ [skipping, high knee, butt kick, high heels for $\sim 10 \mathrm{~s}$ with 30 -s walking in between], $3 \times$ short bursts of accelerations at a subjective "sense of effort" of 7 , 8 , and 9 on a modified Borg CR10 scale, and $2 \times 3$-s sprints at a subjective "sense of effort" of 8 and 9 on the modified Borg CR10 scale) was completed. Afterward, three maximal 5 -s sprints, separated by 2 min of passive recovery, were completed. The best of these three trials was used as the criterion score for the subsequent series to ascertain that no pacing occurred. Finally, after a facemask connected to a portable hypoxic generator (see Altitude simulation section) had been attached on subjects, they were allowed 5 min of free rest (i.e., passive standing) before the repeated sprints protocol. Total hypoxic exposure corresponded to exactly 9 min, with facemask remaining attached during the entire RSA test, including the eight sprints as well as betweensprint recoveries.

Altitude simulation. Normobaric hypoxia was obtained by mixing nitrogen into ambient air under control of $\mathrm{FiO}_{2}$ (Altitrainer, SMTec SA, Nyon, Switzerland). This gasmixing system enriches the inspired air by adding a fixed quantity of nitrogen via a $30-\mathrm{L}$ mixing chamber, with the dilution being constantly controlled by a $\mathrm{PO}_{2}$ probe (with a precision of \pm 0.82 torr and safety set at $\mathrm{FiO}_{2}=9.7 \%$ ). This device allows the production of large quantities of a hypoxic gas mixture (up to $200 \mathrm{~L} \cdot \mathrm{min}^{-1}$ ), with an easily adjustable $\mathrm{O}_{2}$ fraction over a large range, and a short response time (between 15 and $45 \mathrm{~s}$ ), expressed either by the equivalent altitude or by the $\mathrm{O}_{2}$ partial pressure, taking into account the barometric pressure. Subjects, always breathing through the same set-up (also in normoxia), inhaled the mixture contained in the buffer tank through a Hans Rudolph two-way respiratory valve. During testing, they were exposed to near SL $\left(\mathrm{FiO}_{2}=20.9 \%\right), \mathrm{MH}\left(\mathrm{FiO}_{2} \sim 16.8 \%\right.$ corresponding to a simulated altitude of $1800 \mathrm{~m})$, and $\mathrm{SH}\left(\mathrm{FiO}_{2} \sim 13.3 \% ; 3600 \mathrm{~m}\right)$. Although it cannot be completely ruled out, the influence of mask breathing on our RSA outcomes is likely minimal (small resistance and negligible increase in dead space).

Instrumented sprint treadmill. The sprints were performed on an instrumented motorized treadmill (ADAL3D-WR, Medical Development, HEF Tecmachine, Andrézieux-Bouthéon, France). Briefly, it is mounted on a highly rigid metal frame fixed to the ground through four piezoelectric force transducers (KI 9077b; Kistler, Winterthur, Switzerland) and installed on a specially engineered concrete slab to ensure maximal rigidity of the supporting ground. This motorized treadmill allows subjects to sprint and produce acceleration and high running velocities due to the use of a constant motor torque $(17,35,36)$. This corresponded to the motor torque necessary to overcome the friction on the belt due to subject's body weight, which was set to $160 \%$ of the default torque after preliminary testing. This default torque value was selected for allowing subjects to sprint in a comfortable manner and produce their maximal effort without risking loss of balance. It was measured by requiring the subject to stand unmoving at the center of the treadmill's belt and by increasing the driving torque until observing a movement of the belt greater than $2 \mathrm{~cm}$ over $5 \mathrm{~s}$.

A single-pass waist and a stiff rope (i.e., $1 \mathrm{~cm}$ in diameter, $\sim 2 \mathrm{~m}$ length) were used to tether subjects to the $0.4-\mathrm{m}$ vertical rail anchored to the wall behind them. An additional safety harness attached to an overhead suspension (i.e., with sufficient slack not to impede natural running mechanics) was fastened to the subjects to support them above the treadmill belt in the event of a fall. When correctly attached, they were required to lean forward in a typical and standardized crouched sprint-start position with their left foot forward. This starting position was used and standardized all along the sprint series. After a 5-s countdown ("5 s, 3-2-1Go" given by both visual and audio instructions by the same investigator), the treadmill was released, and the belt began to accelerate as subjects applied a positive horizontal force.

RSA. The RSA test consisted of performing eight 5-s treadmill sprints interspersed by 25 -s of passive recovery. The construct of the 5- to 25-s repeated sprint design was used to match one of the most common effort-rest ratios seen in the literature (e.g., [4]). RSA was assessed from net power output in the horizontal direction $\left(P_{\mathrm{P}}\right)$ data using three scores: the largest (i.e., during the first sprint in all cases) $P_{\mathrm{P}}$, the cumulated $P_{\mathrm{P}}$ over the eight sprints (i.e., sum of the eight sprints), and the sprint decrement score [i.e., ([cumulated $P_{\mathrm{P}} /\left(\right.$ largest $\left.\left.\left.\left.P_{\mathrm{P}} \times 8\right)\right]-1\right) \times 100\right](19)$.

Mechanical variables. Data were continuously sampled at $1000 \mathrm{~Hz}$ over the sprints, allowing the determination 
of the beginning of the sprints (defined as the moment the belt velocity exceeded $0.2 \mathrm{~m} \cdot \mathrm{s}^{-1}$ ). After appropriate filtering (Butterworth-type 30-Hz low-pass filter), instantaneous data of vertical, net horizontal, and resultant (i.e., total) GRF were averaged for each support phase (vertical force higher than $30 \mathrm{~N})$ over the 5 -s sprints $\left(F_{\mathrm{V}}, F_{\mathrm{H}}\right.$, and $F_{\mathrm{Tot}}$, respectively) and expressed in body weight. The index of force application technique $\left(D_{\mathrm{RF}}\right)$ representing the decrement in ratio of forces $\left(\mathrm{RF}=F_{\mathrm{H}} / F_{\mathrm{T}}\right)$ with the increasing belt velocity $\left(V, \mathrm{~m} \cdot \mathrm{s}^{-1}\right)$ was computed as the slope of the linear RF- $V$ relationship calculated from the step-averaged values between the second step and the step at top $V(34)$. These data were completed by measurements of the main step kinematic variables: $t_{\mathrm{c}}(\mathrm{s})$, aerial time $\left(t_{\mathrm{a}}, \mathrm{s}\right), t_{\mathrm{swing}}(\mathrm{s})$, step frequency $\left(S_{\mathrm{F}}, \mathrm{Hz}\right)$, and step length $\left(S_{\mathrm{L}}, \mathrm{m}\right)$. Last, for each 5-s sprint, $F_{\mathrm{H}}$ was used with the corresponding average $V$ to compute $P_{\mathrm{P}}\left(P_{\mathrm{P}}=F_{\mathrm{H}} V, \mathrm{~W} \cdot \mathrm{kg}^{-1}\right)$.

A linear spring-mass model of running (33) was used to investigate the main mechanical parameters characterizing the lower limbs behavior during running. Vertical stiffness $\left(K_{\mathrm{vert}}, \mathrm{kN} \cdot \mathrm{m}^{-1}\right)$ was calculated as the ratio of peak vertical force $\left(F z_{\max }, \mathrm{N}\right)$ to the vertical maximal downward displacement of $\mathrm{CM}(\Delta z, \mathrm{~m})$, which was determined by the double integration of vertical acceleration of center of mass over time during ground contact. Leg stiffness, the stiffness of the leg spring $\left(K_{\text {leg }}, \mathrm{kN} \cdot \mathrm{m}^{-1}\right)$, was calculated as the ratio of $F z_{\max }$ to the maximum leg spring compression $[\Delta L=\Delta z+$ $\left.L_{0}-\sqrt{ } L_{0}^{2}-\left(0.5 V t_{\mathrm{c}}\right)^{2}, \mathrm{~m}\right]$. Initial leg length $\left(L_{0}\right.$, great trochanter to ground distance in a standing position) was determined from subject's stature as $L_{0}=0.53 \times$ stature (33).

Physiological responses. HR was monitored telemetrically with a Polar transmitter-receiver (Wearlink T-31; Polar Electro Oy, Kempele, Finland) and recorded every $5 \mathrm{~s}$. Pulse $\mathrm{O}_{2}$ saturation $\left(\mathrm{SpO}_{2}\right)$ was monitored via fingertip pulse oximetry (Palmsat 2500, Nonin Medical Inc., Plymouth, USA). HR and $\mathrm{SpO}_{2}$ were obtained before (i.e., after a 5-min seated period) and at the end of the warm-up procedure (i.e., after $5 \mathrm{~min}$ of rest while breathing the hypoxic mixture, just before starting the RSA test). Both HR watch (RS400, Polar Electro $\mathrm{Oy}$ ) and oximeter receiver were attached on the handrails on the sides of the treadmill in a manner to not allow subjects to view any data, according to the blinding procedure. Together with $\mathrm{HR}$ and $\mathrm{SpO}_{2}$, ratings of perceived exertion (RPE) values were recorded using the Borg 6-20 scale (i.e., $6=$ no exertion at all, $20=$ maximal exertion) exactly $10 \mathrm{~s}$ after each sprint. A capillary blood sample was taken from the fingertip and analyzed for blood lactate concentration ([La]) with the Lactate Pro (LT-1710, Arkray, Japan) portable analyzer before the warm-up and 2 min after the RSA test.

Statistical analyses. Each sprint trial included 15-18 ground contacts. After excluding the last two ground contacts, the remaining three last consecutive steps were used for final analysis of sprint kinetics/kinematics and springmass characteristics (7). Importantly, the effects of treadmill sprints repetition (fatigue) on performance and mechanical outcomes do not differ between early, middle, or late phases of 5-s sprints similar to those performed here (16).

Values are expressed as mean $\pm \mathrm{SD}$. Two-way repeatedmeasures ANOVA (condition [SL, $\mathrm{MH}$, and $\mathrm{SH}] \times$ time [sprint number 1, 2, 3, 4, 5, 6, 7, and 8]) were used to compare physiological/perceptual, running performance, and mechanical responses. Outcome variables were tested using Mauchly's procedure for sphericity. Whenever the data violated the assumption of sphericity, $P$ values and adjusted degrees of freedom based on Greenhouse-Geisser correction were reported instead. Where significant effects were established, pairwise differences were identified using the Bonferroni post hoc analysis procedure adjusted for multiple comparisons. All statistical calculations were performed using SPSS statistical software V.21.0 (IBM Corp., Armonk, NY, USA). The significance level was set at $P<0.05$.

\section{RESULTS}

Blinding procedure. Observations that a) only 4 out of 13 participants assumed that they were exposed to SL, $\mathrm{MH}$, or $\mathrm{SH}$ at the end of the first, second, and third experimental session (i.e., treatment order), and b) only 12 out of a possible 39 sessions were correctly identified, together indicate that the blinding procedure was successful.

Responses to exercise. When reporting to the laboratory, subjects displayed similar resting HR (pooled values: $67 \pm 11 \mathrm{bpm} ; P=0.98), \mathrm{SpO}_{2}(97.3 \% \pm 1.2 \% ; P=0.72)$, and [La] $\left(1.4 \pm 0.4 \mathrm{mmol} \cdot \mathrm{L}^{-1} ; P=0.89\right)$ values across visits. At the end of the warm-up procedure $(5 \mathrm{~min}$ after breathing the hypoxic mixture), HR tended to be higher under hypoxic conditions (SL: $94 \pm 15$ bpm; MH: $102 \pm 12$ bpm; SH: $102 \pm 17 \mathrm{bpm} ; P=0.06)$, whereas $\mathrm{SpO}_{2}$ was significantly $(P<0.001)$ reduced under SH $(88.8 \% \pm 2.9 \%)$ compared with both SL $(95.5 \% \pm 1.1 \%)$ and MH $(94.5 \% \pm 1.2 \%)$, with also no significant $(P=0.07)$ difference between SL and $\mathrm{MH}$.

HR increased significantly from the first to the fifth repetition $(P<0.001)$, with no further change thereafter, independently of the conditions (Fig. 1). With every increase in hypoxia, severity corresponded significantly lower $(P<$ $0.001) \mathrm{SpO}_{2}$ values (Fig. 1). Although fluctuations of $\mathrm{SpO}_{2}$ values for SL condition remained within $1 \%$ of sprint $1(P=$ $0.97), \mathrm{SpO}_{2}$ values decreased significantly from the first to the last repetition in both $\mathrm{MH}$ and $\mathrm{SH}$ trials $(-5.5 \% \pm 4.9 \%$ and $-7.9 \% \pm 4.2 \%$, respectively; both $P<0.05)$. RPE increased significantly $(P<0.001)$ across all conditions (Fig. 1), but significantly higher $(P<0.01)$ RPE values were rated for sprint 8 in SH (19.1 \pm 0.8$)$ compared with SL (18.5 \pm 1.2) and $\mathrm{MH}(18.1 \pm 1.6)$. Exercise-induced increase in [La] $(P<0.001)$ was not different $(P=0.40)$ between conditions with values of $9.9 \pm 1.7,10.4 \pm 1.8$, and $10.7 \pm$ $2.1 \mathrm{mmol} \cdot \mathrm{L}^{-1}$ reached $2 \mathrm{~min}$ after the RSA test in SL, MH and $\mathrm{SH}$, respectively.

RSA and other running performance outcomes. During the RSA test, the $95 \%$ criterion score 

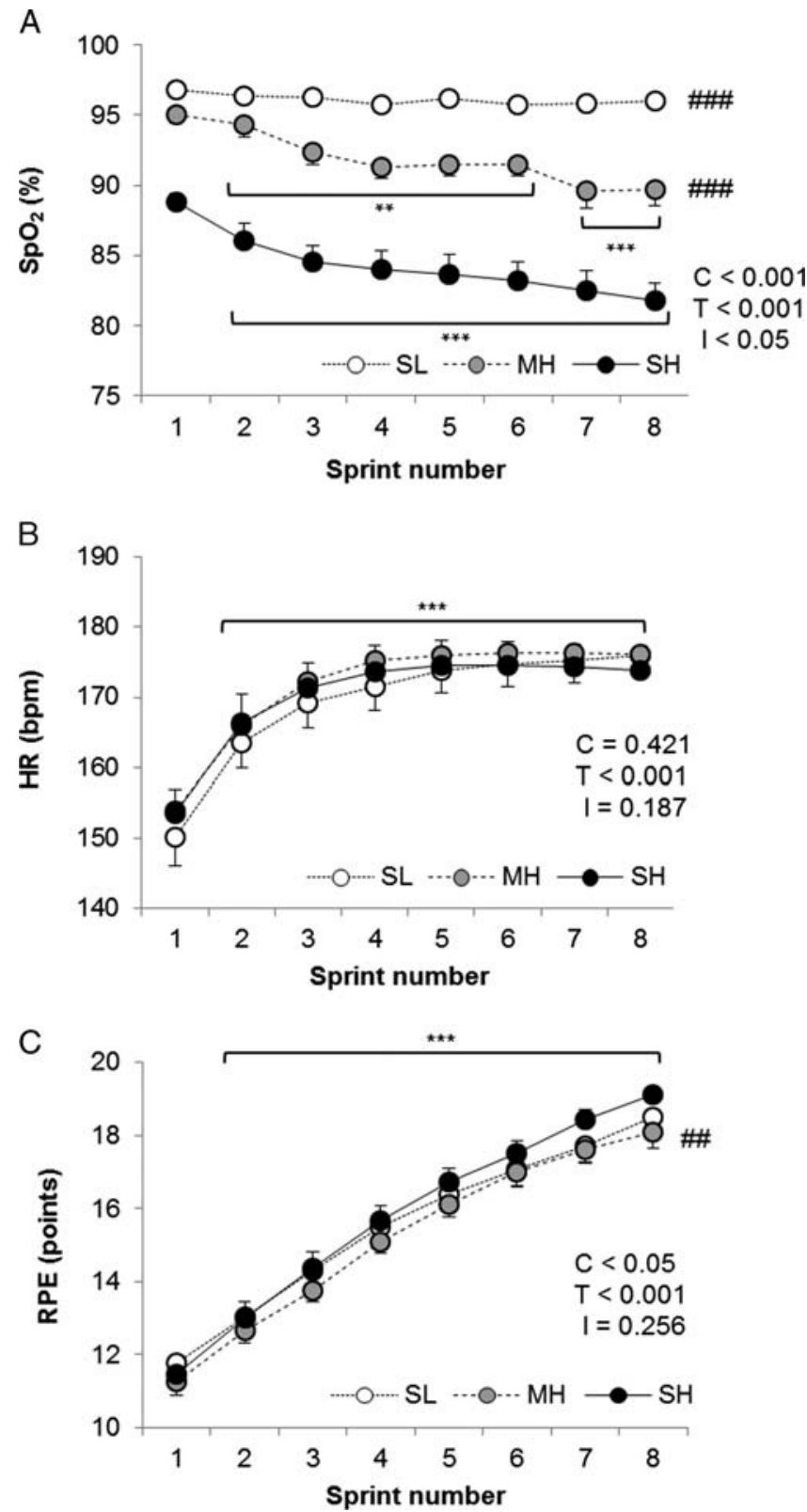

FIGURE 1-Pulse oxygen saturation $\left(\mathrm{SpO}_{2} ; \mathrm{A}\right)$, HR (B), and perceptual (RPE; C) responses during the RSA test. Values are mean $\pm \mathrm{SD}, N=13$. Data are presented for $\mathrm{SL}\left(\mathrm{FiO}_{2}=\mathbf{2 0 . 9 \%}\right)$, $\mathrm{MH}$

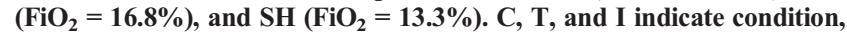
time, and interaction effects. Significantly different from sprint 1 , $* * P<0.01$ and $* * * P<0.001$. Significantly different from $\mathrm{SH}, \# \# P<0.01$ and $\# \# P<0.001$.

was satisfied by all participants in the three testing conditions (SL: $99.5 \% \pm 2.0 \%$; MH: $101.0 \% \pm 5.9 \%$; SH: $100.7 \% \pm 4.2 \%)$. This corresponded to a similar $V$ and $P_{\mathrm{P}}$ during the first sprint in all three trials (SL: $6.39 \pm$ $0.28 \mathrm{~m} \cdot \mathrm{s}^{-1}$ and $13.39 \pm 2.18 \mathrm{~W} \cdot \mathrm{kg}^{-1} ; \mathrm{MH}: 6.44 \pm 0.25 \mathrm{~m} \cdot \mathrm{s}^{-1}$ and $13.15 \pm 1.86 \mathrm{~W} \cdot \mathrm{kg}^{-1}$; SH: $6.35 \pm 0.33 \mathrm{~m} \cdot \mathrm{s}^{-1}$ and $12.73 \pm$ $1.95 \mathrm{~W} \cdot \mathrm{kg}^{-1} ; P=0.71$ and 0.70 , respectively). Subsequently, progressive reduction in $V(P<0.001)$ and $P_{\mathrm{P}}(P<$ 0.001 ) occurred from sprints 1 to 8 , irrespective of the conditions, yet with larger decrease in $\mathrm{SH}(-11.2 \% \pm$ $4.1 \%$ and $-22.9 \% \pm 11.6 \%$, respectively) compared with
SL $(-8.5 \% \pm 4.0 \%, P<0.05$, and $-14.9 \% \pm 14.7 \%, P<$ $0.001)$ and $\mathrm{MH}(-11.1 \% \pm 4.1 \%, P<0.05$, and $-15.8 \% \pm$ $7.5 \%, P<0.01$ ) (Fig. 2). Cumulated $P_{\mathrm{P}}$ was lower in $\mathrm{SH}$ $\left(88.28 \pm 16.13 \mathrm{~W} \cdot \mathrm{kg}^{-1}\right)$ compared with $\mathrm{SL}(95.31 \pm$ $\left.17.06 \mathrm{~W} \cdot \mathrm{kg}^{-1},-7.3 \% \pm 5.5 \%, P<0.001\right)$ and $\mathrm{MH}(94.76 \pm$ $\left.14.77 \mathrm{~W} \cdot \mathrm{kg}^{-1},-7.1 \% \pm 5.9 \%, P<0.01\right)$, with no difference between SL and MH $(+0.1 \% \pm 8.0 \%, P=1.00)$. Sprint decrement score did not differ significantly $(P=0.49)$ between SL $(-10.9 \% \pm 8.1 \%)$, $\mathrm{MH}(-9.8 \% \pm 8.0 \%)$, and SH $(-13.5 \% \pm 7.8 \%)$.

Running kinetics and kinematics. $F_{\mathrm{V}}, F_{\mathrm{H}}$, and $F_{\mathrm{Tot}}$ decreased significantly $(P<0.001)$ from the first to the last repetition in all conditions (pooled values: $-2.4 \% \pm 1.9 \%$, $-8.6 \% \pm 6.5 \%$, and $-2.4 \% \pm 1.9 \%$, respectively) (Fig. 3). $F_{\mathrm{H}}$ was significantly lower in SH compared with SL and MH $(-4.9 \% \pm 5.9 \%$ and $-5.2 \% \pm 5.4 \%$, respectively; $P<$ $0.01)$, whereas nonsignificant trends were observed for $F_{\mathrm{v}}$ $(P=0.09)$ and $F_{\text {Tot }}(P=0.07)$ (Fig. 3).

$D_{\mathrm{RF}}$ significantly decreased across repetitions (pooled value: $-7.7 \% \pm 9.7 \%, P<0.001)$ so that the RF $-V$ relationship
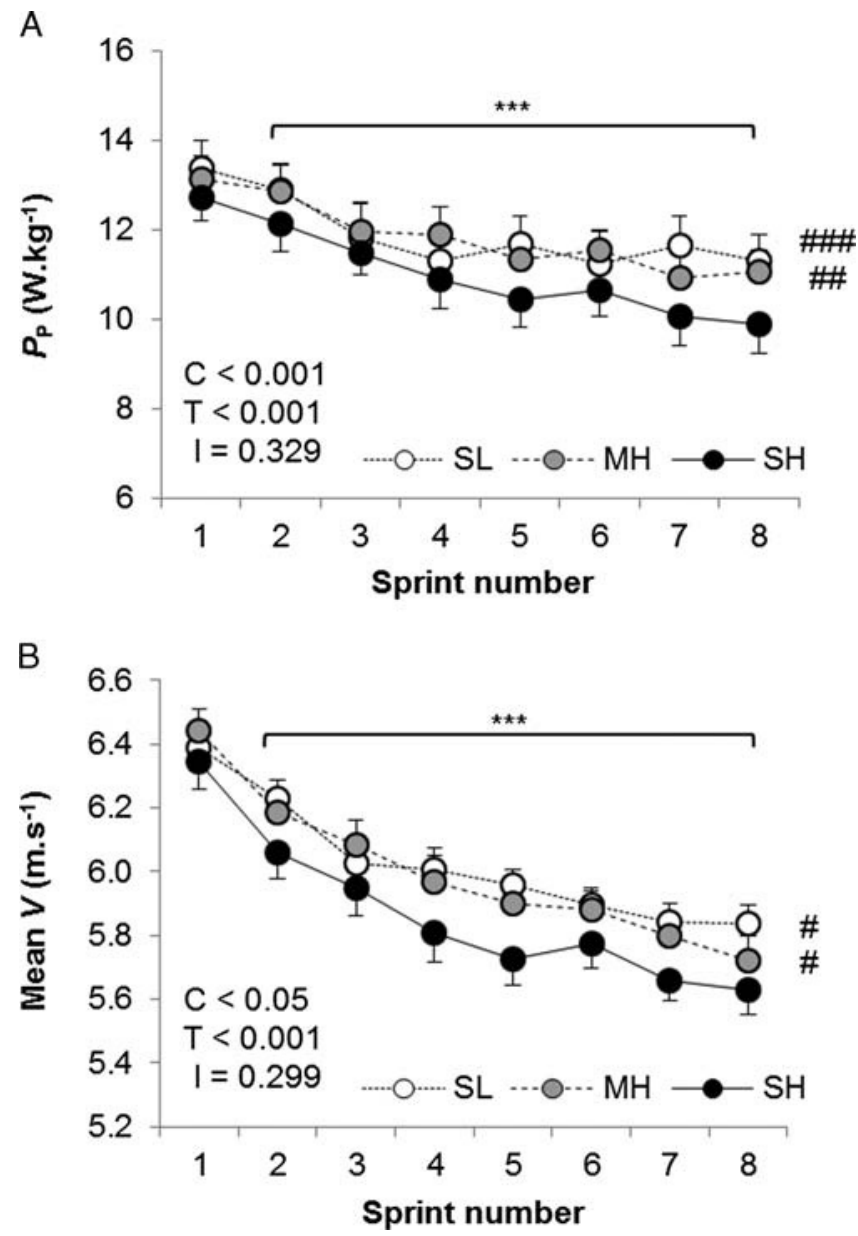

FIGURE 2-Propulsive power $\left(P_{\mathrm{P}}, \mathrm{A}\right)$ and mean velocity $(V, \mathrm{~B})$ during the RSA test. Values are mean $\pm \mathrm{SD}, N=13$. Data are presented for $\mathrm{SL}\left(\mathrm{FiO}_{2}=20.9 \%\right), \mathrm{MH}\left(\mathrm{FiO}_{2}=16.8 \%\right)$, and $\mathrm{SH}\left(\mathrm{FiO}_{2}=13.3 \%\right)$. C, $T$, and $I$ indicate condition, time, and interaction effects. Significantly different from sprint $1, * * * P<0.001$. Significantly different from SH, \#P<0.05, \#\#P<0.01, and \#\#\#<0.001. 

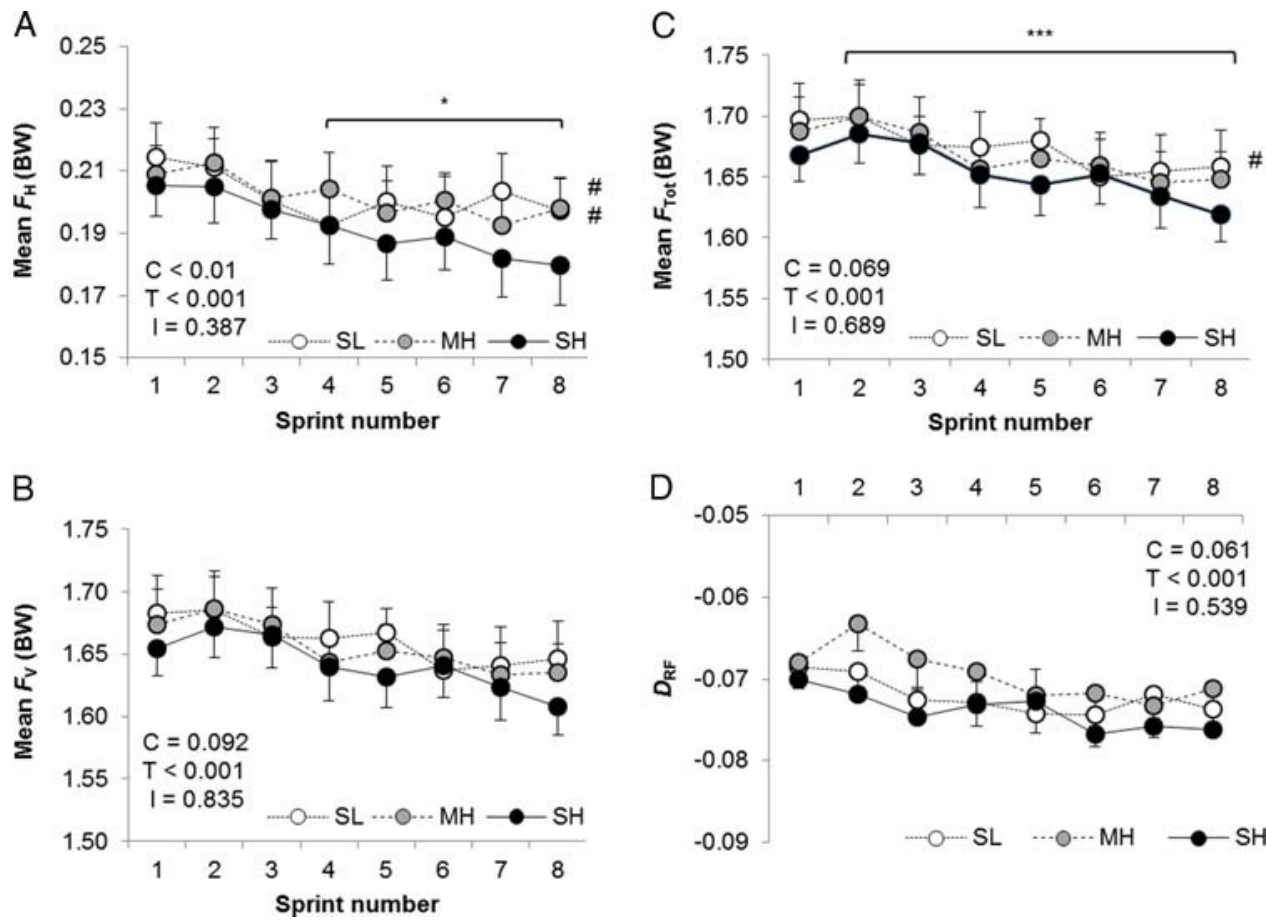

FIGURE 3-Kinetic characteristics (net horizontal forces $\left[F_{\mathrm{H}} ; \mathrm{A}\right]$, mean vertical forces $\left[F_{\mathrm{V}} ; \mathrm{B}\right]$, and mean total forces $\left[\boldsymbol{F}_{\mathrm{Tot}}\right.$; $\left.\mathrm{C}\right]$ ) and index of force application technique $\left(D_{\mathrm{RF}}\right.$; D) during the RSA test. Values are mean $\pm \mathrm{SD}, \mathrm{N}=\mathbf{1 3}$. Data are presented for $\left.\mathrm{SL}_{(\mathrm{FiO}}=\mathbf{2 0 . 9} \%\right), \mathrm{MH}\left(\mathrm{FiO}{ }_{2}=16.8 \%\right)$, and $\mathrm{SH}\left(\mathrm{FiO}_{2}=13.3 \%\right)$. C, T, and $\mathrm{I}$ indicate condition, time, and interaction effects. Significantly different from sprint $1, * P<0.05, * * P<0.01$, and $* * * P<0.001$. Significantly different from $\mathrm{SH}, \# P<0.05$.

became steeper with fatigue, whereas these changes tended to differ $(P=0.06)$ between SL $(-8.6 \% \pm 14.2 \%)$, MH $(-5.0 \% \pm$ $12.0 \%)$, and SH (-9.5\% $\pm 15.3 \%)$ (Fig. 3).

$t_{\mathrm{c}}$ was the only mechanical variable displaying a significant interaction between time and condition with a larger magnitude of fatigue-induced changes seen in SH compared with SL and $\mathrm{MH}(+4.0 \% \pm 2.9 \%, P<0.001$, and $+3.3 \% \pm$ $3.6 \%, P<0.05$, respectively). Compared with $\mathrm{SL}$ and $\mathrm{MH}$, greater alterations in $\mathrm{SH}$ were found for $t_{\text {swing }}(+1.5 \% \pm$ $2.5 \%$ and $+2.1 \% \pm 2.7 \%$, respectively; both $P<0.05)$ and $S_{\mathrm{F}}$ $(-2.3 \% \pm 2.0 \%, P<0.01$, and $-2.3 \% \pm 2.8 \%, P<0.05$, respectively) but not for $t_{\mathrm{a}}(+0.1 \% \pm 5.4 \%$ and $+1.1 \% \pm$ $4.9 \%$, respectively; $P=0.52)$ and $S_{\mathrm{L}}(-0.6 \% \pm 3.8 \%$ and $+0.1 \% \pm 2.9 \%$, respectively; $P=0.64$ ) (Fig. 4 ).

Spring-mass parameters. Although $F z_{\max }$ significantly $(-2.9 \% \pm 1.9 \%, P<0.001)$ decreased, both $\Delta z$ and $\Delta L$ significantly increased (conditions pooled: $+19.8 \% \pm 6.2 \%$, $P<0.001$, and $+5.3 \% \pm 3.5 \%, P<0.05$, respectively) from the first to the last sprint (Fig. 5). Consequently, $K_{\text {vert }}$ and $K_{\text {leg }}$ significantly (conditions pooled: $-18.5 \% \pm 5.0 \%$ and $-7.4 \% \pm$ $4.1 \%$, respectively; both $P<0.001)$ decreased with fatigue. In reference to SL and $\mathrm{MH}, \Delta z$ values were larger $(+5.1 \% \pm 4.4 \%$, $P<0.01$, and $+5.2 \% \pm 6.4 \%, P<0.05$, respectively) and $K_{\text {vert }}$ smaller $(-6.0 \% \pm 3.9 \%, P<0.001$, and $-5.1 \% \pm 5.7 \%, P<$ 0.01 , respectively) in $\mathrm{SH}$, whereas only a tendency for lower $F z_{\max }$ values $(-1.5 \% \pm 4.4 \%$ and $-0.8 \% \pm 6.4 \%$, respectively; $P=0.051$ ) was observed (Figs. 5 and 6). Figure 6 shows the comparison of the main averaged running mechanical data for the eight sprints in $\mathrm{MH}$ and $\mathrm{SH}$ in reference to SL.

\section{DISCUSSION}

The present study specifically examined how the level of normobaric hypoxia severity affects performance of repeated treadmill sprints and associated mechanical parameters. The main results were that in $\mathrm{SH}\left(\mathrm{FiO}_{2}=13.3 \% ; \sim 3600 \mathrm{~m}\right)$, but not $\mathrm{MH}\left(\mathrm{FiO}_{2}=16.8 \% ; \sim 1800 \mathrm{~m}\right)$, impairments in RSA and in accompanying kinetics/kinematics and spring-mass characteristics exceed those observed at SL $\left(\mathrm{FiO}_{2}=20.9 \%\right)$.

In this study, both $\mathrm{MH}$ and $\mathrm{SH}$ had no detrimental effect on the initial sprint performance compared with SL. This was expected because performance of single sprint of short duration $(\leq 10 \mathrm{~s})$ largely depends on neuromuscular recruitment/activation and intramuscular energy stores $(2,43)$. However, in partial agreement with previous studies $(5,23)$, $P_{\mathrm{P}}$ was lower in $\mathrm{SH}$, but not in $\mathrm{MH}$, compared with $\mathrm{SL}$ and resulted in shorter cumulated $P_{\mathrm{P}}$ and larger sprint decrement score during the set of repeated sprints in $\mathrm{SH}$ compared with $\mathrm{SL}$ and $\mathrm{MH}$. Although it remains unclear how the present data would fit with elite team sport athletes (38) because they may experience a larger $\mathrm{O}_{2}$ desaturation in hypoxia (31) that would exacerbate performance alteration for a given simulated altitude, our results (from recreational athletes) suggest that RSA performance decrements with increased hypoxia severity did not follow a monotonic (i.e., linear) pattern. Given the importance to maintain maximal $P_{\mathrm{P}}$ levels across sprints repetition during an RSA protocol (19), one may postulate that $\mathrm{SH}$ is less suitable than $\mathrm{MH}$ for training purpose, although larger physiological effects associated with 

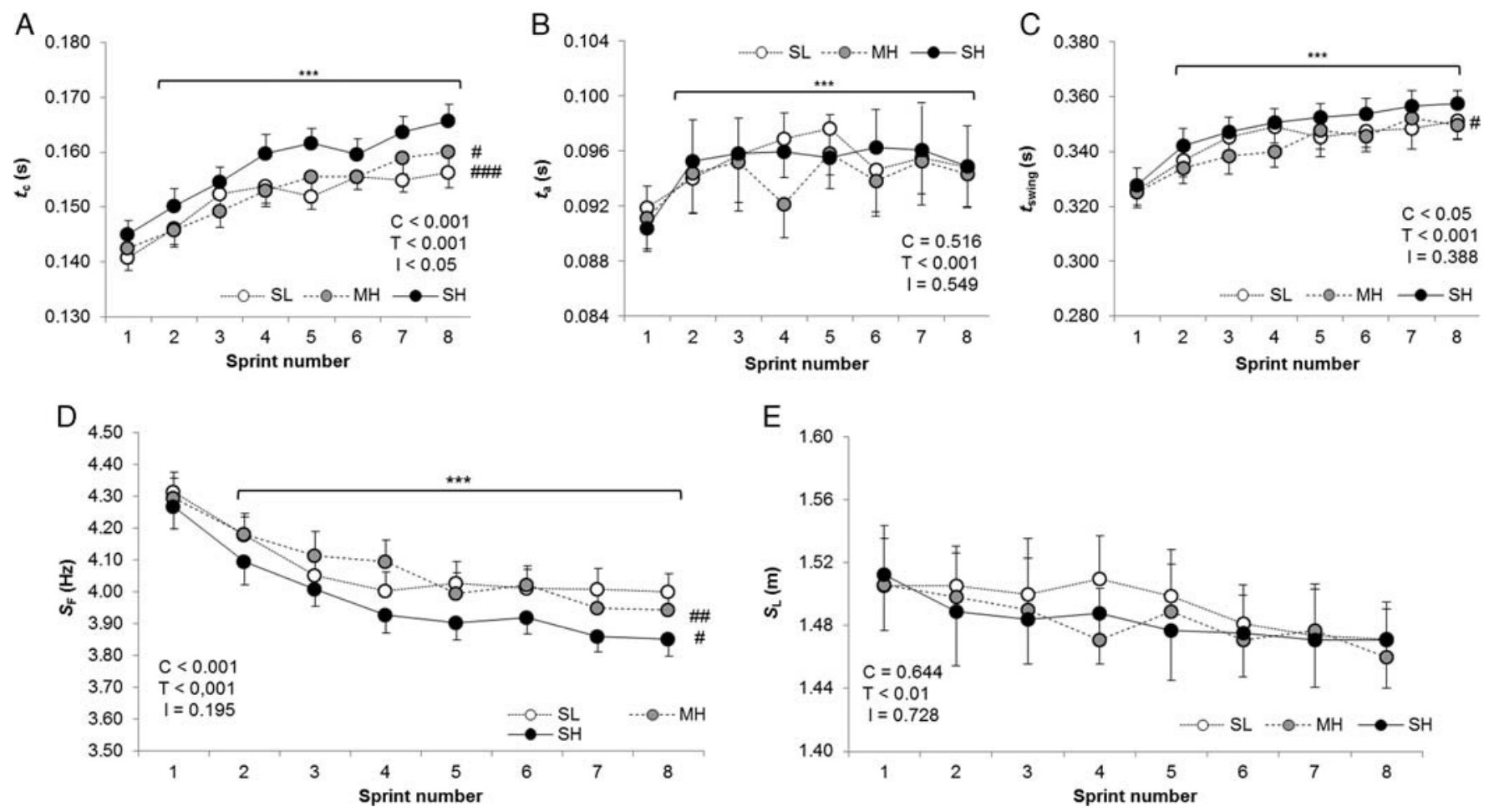

FIGURE 4-Kinematic characteristics [contact time $\left(t_{\mathrm{c}} ; \mathrm{A}\right)$, aerial time $\left(t_{\mathrm{a}} ; \mathrm{B}\right)$, swing time $\left(t_{\mathrm{swing}} ; \mathrm{C}\right)$, step frequency $\left(S_{\mathrm{F}} ; \mathrm{D}\right)$ and step length $\left.\left(S_{\mathrm{L}} ; \mathrm{E}\right)\right]$ during the RSA test. Values are mean $\pm \mathrm{SD}, N=13$. Data are presented for $\mathrm{SL}\left(\mathrm{FiO}_{2}=\mathbf{2 0 . 9} \%\right), \mathrm{MH}\left(\mathrm{FiO}_{2}=\mathbf{1 6 . 8} \%\right)$, and $\mathrm{SH}(\mathrm{FiO}=13.3 \%)$. $\mathrm{C}, \mathrm{T}$, and $\mathrm{I}$ indicate condition, time, and interaction effects. Significantly different from sprint $1,{ }^{* * *} P<0.001$. Significantly different from $\mathrm{SH}, \# P<0.05$, \#\#P $<.01$, and \#\#P $<0.001$.

SH versus $\mathrm{MH}$ cannot be ruled out. In this view, a notable finding is that most of the alterations in sprint performance and accompanying running mechanics (discussed in the next paragraph) occurred within the first half (i.e., sprints 1 to 4 ) of the RSA test with smaller changes during the second part (i.e., sprints 5 to 8). This phenomenon is particularly notable in $\mathrm{SH}$ condition. This appears in line with the biphasic profile (i.e., a gradual decrease in power output during the first sprints followed by a plateau-like phase) previously observed during repeated cycling sprints (i.e., $10 \times 10 \mathrm{~s}$ all-out sprints with $30 \mathrm{~s}$ of passive recovery) (26). Of interest is that $\mathrm{SpO}_{2}$ values remained $>90 \%$ in $\mathrm{MH}$, whereas initial $\mathrm{SpO}_{2}$ values were $<90 \%$ in $\mathrm{SH}$ and decreased to $\sim 82 \%$ (ranging from $76 \%$ to $89 \%$ ) across RSA test repetitions. These values are higher than the $70 \%-75 \% \mathrm{SpO}_{2}$ values suggested as a critical "threshold" (derived from self-paced exercises) where central nervous system hypoxia would primarily (e.g., over peripheral muscle fatigue) influence exercise performance (1). Recent evidence using manipulations of preexisting fatigue levels (26) and hypoxia severity (4) would support the view that power output and surface electromyography are adjusted during repeated sprinting to limit the development of peripheral fatigue beyond a constant threshold.

It is generally accepted that, with an acute reduced $\mathrm{O}_{2}$ availability (such as in normobaric hypoxia), there is an increased reliance on nonoxidative glycolysis (5) and PCr hydrolysis rate (24). As such, cycling (2) and treadmill $(5,23)$ hypoxia-induced $\left(\mathrm{FiO}_{2}\right.$ ranging from $14 \%$ to $\left.16 \%\right)$ RSA performance decrements were previously associated with higher [La] $(2,5,23)$, HR $(2,5)$, and RPE (23). Here, the responses (i.e., [La], HR, and RPE) to exercise followed a similar trend, albeit [La] and end-exercise HR values were not significantly different between conditions, as previously demonstrated during RSA tests $(2,23)$. Of note, in line with the above-mentioned performance measures, HR displayed a plateau-like phase from sprint 5 . Furthermore, RPE was only significantly higher in SH compared with other conditions during the last sprint repetition. This is despite subjects being constantly reminded during between-sprint recoveries of each of the three conditions that subjective awareness of effort expended during the next sprint bout must be maximal. Importantly, this larger perceived peripheral discomfort (RPE) in the more severe hypoxic condition occurred despite lower fatigue resistance. Fatigue during RSA is a disabling symptom in which physical and cognitive functions are limited by interactions between objective (performance) and subjective (effort perception) signals with hypoxia severity influencing the nature of this relationship.

Mechanical alterations during normoxic RSA tests have been well described in recent studies (treadmill [32,34,36], force plate [27,29,37,41], and overground [7,20,21,25]). Briefly, alterations in sprinting mechanics (i.e., kinetics: reduction in $F_{\mathrm{H}}$ production; kinematics: lengthening in $t_{\mathrm{c}}$ and $t_{\text {swing, }}$, decrease in $S_{\mathrm{F}}$; spring-mass characteristics: increase in $\Delta z$, decline in $K_{\text {vert }}$ ) and force application technique (i.e., decrease in $D_{\mathrm{RF}}$ ) occur concomitantly with a reduced 

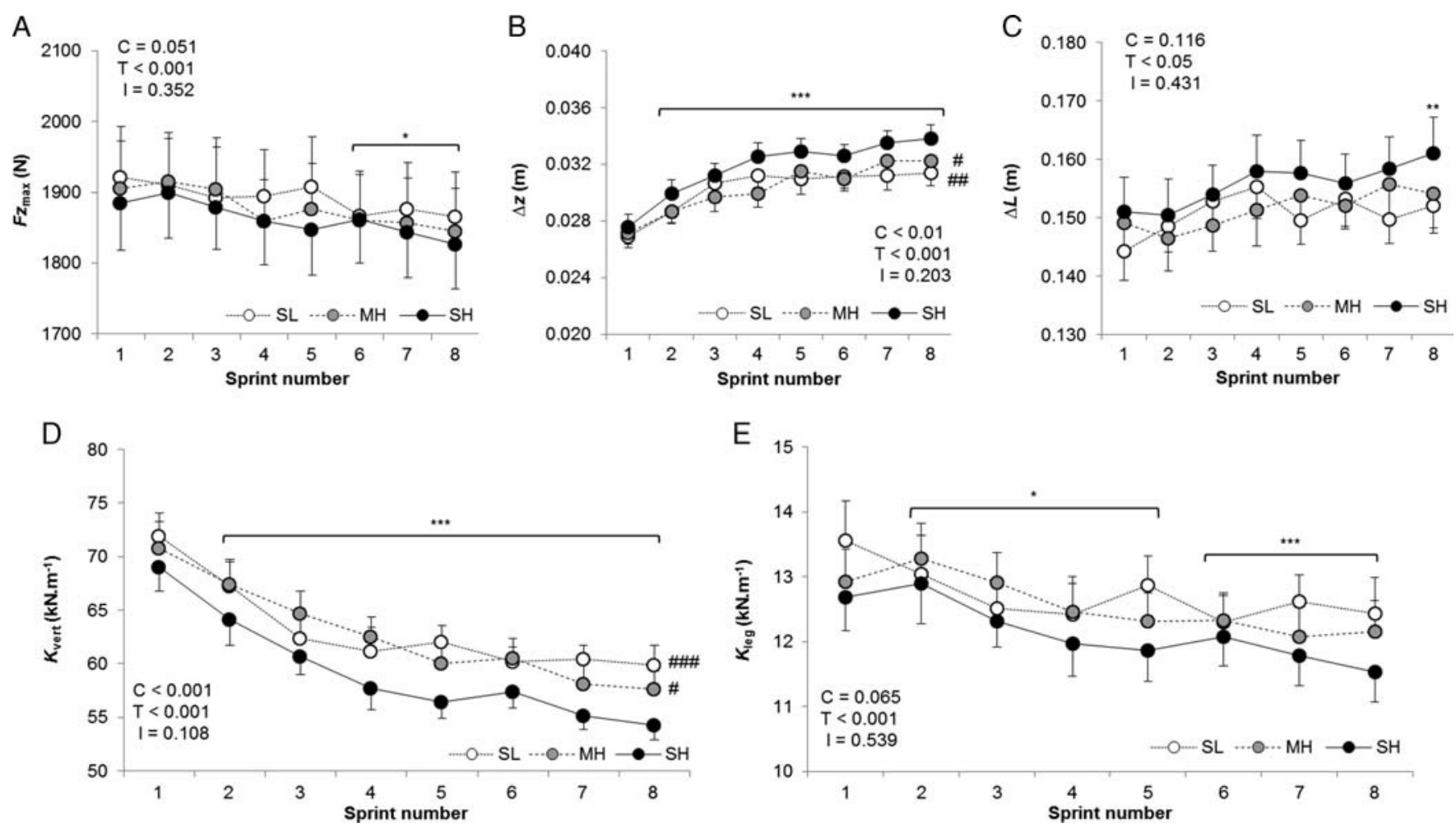

FIGURE 5-Spring-mass behavior (peak vertical forces $\left[F z_{\text {max }} ; \mathrm{A}\right]$, vertical maximal displacement of $\mathrm{CM}[\Delta z ; \mathrm{B}]$, maximum leg spring compression $[\Delta L ; C]$, vertical stiffness $\left[K_{\mathrm{vert}} ; \mathrm{D}\right]$, and leg stiffness $\left.\left[K_{\mathrm{leg}} ; \mathrm{E}\right]\right)$ during the RSA test. Values are mean $\pm \mathrm{SD}, N=13$. Data are presented for SL $\left(\mathrm{FiO}_{2}=20.9 \%\right)$, $\mathrm{MH}\left(\mathrm{FiO}_{2}=16.8 \%\right)$, and $\mathrm{SH}\left(\mathrm{FiO}_{2}=13.3 \%\right)$. C, T, and I indicate condition, time, and interaction effects. Significantly different from sprint $1, * P<0.05, * * P<0.01$, and $* * * P<0.001$. Significantly different from $\mathrm{SH}, \# P<0.05$, \#\#P<0.01, and \#\#\#P 0.001.

performance (i.e., decreases in $P_{\mathrm{P}}, V$, and sprint decrement score) during repeated sprints. With similar adjustments occurring irrespectively from the conditions, our results confirm a deteriorated ability to tolerate ground impact/stretch loads as fatigue develops with sprint repetitions. Of particular relevance, and because i) increasing $V$ can be achieved by pushing on the ground more forcefully $\left(S_{\mathrm{L}}\right)$, more frequently $\left(S_{\mathrm{F}}\right)$ or by combining both schemes (42); ii) a more forceful ground contact results in a longer $S_{\mathrm{L}}(11)$; and iii) $S_{\mathrm{L}}$ is inversely proportional to $S_{\mathrm{F}}(25)$, our results clearly demonstrate that $t_{\mathrm{c}}$ is the main kinematic variable explaining the fatigue-induced reduction in $S_{\mathrm{F}}$ (and to a lesser extent $S_{\mathrm{L}}$ ).

Regarding the effect of hypoxia severity, $\mathrm{SH}$ further worsened stride efficiency compared with SL and MH. With the exception of $t_{\mathrm{c}}$, which displayed an interaction effect, all other mechanical variables displayed only a main effect of the condition. Of note, the magnitude of sprints 1 to 8 reductions for $F_{\mathrm{H}}$ was three times larger than for $F_{\mathrm{Tot}}$ in $\mathrm{SH}$ compared with SL and MH, in agreement with previous RSA studies conducted at SL $(20,36)$. This was also accompanied by a deteriorated $D_{\mathrm{RF}}$ across sprint repetitions and exacerbated by hypoxia severity, thereby indicating progressively shorter and less effective acceleration phases across repetitions. This, added to the fact that vertical impulse was not related to acceleration performance in highly trained sprinters (37), is of particular relevance as applying ground reaction impulse in a more horizontal direction is crucial for an effective ability to accelerate from a standing start $(34,36)$ and explains $44 \%$ and $61 \%$ of the variance of $V$ at $8 \mathrm{~m}$ (27) and $16 \mathrm{~m}$ (25) from the start. Altogether, these findings therefore corroborate the biomechanical assumption that applying forward-oriented total force against the ground is a key determinant of repeated sprinting $(20,36)$. This reliance on $F_{\mathrm{H}}$ production during all-out sprinting (29) has recently been confirmed in elite sprinters using both treadmill (32) and force plate protocols (41). Although during the initial steps of sprinting (acceleration phase) the biomechanical objective is to maximize the propulsive component of the GRF (39), such observations do lend some support to the proposed combination of ground force production and $S_{\mathrm{F}}$ (42) or vice versa.

Although it has been recently challenged at top running velocities in elite individuals (10), modeling the spring-mass behavior remains valid and reliable (17) at slower maximal running velocities than those reached by world-class sprinters (41). This model remains an interesting descriptor of the stance-limb mechanics during our RSA protocol in a group of recreational team sport athletes. Although the musculotendinous stiffness is believed to be a vital component of setting $S_{\mathrm{F}}$ during sprinting (12), the substantial impairment of the main kinematics and spring-mass factors of stride efficiency (i.e., $t_{\mathrm{c}}, t_{\mathrm{swing}}, \Delta z$ and $K_{\mathrm{vert}}$ ) induced by $\mathrm{SH}$, compared with SL and $\mathrm{MH}$, confirms that the maintenance of $K_{\text {vert }}$ values under fatigue is paramount to minimize the increase in $t_{\mathrm{c}}$ and concomitant decrease in $S_{\mathrm{F}}(7,20,21)$. The 


Mean $F_{\mathrm{V}}(\mathrm{BW})$
Mean $F_{\mathrm{H}}(\mathrm{BW})$
Mean $F_{\text {Tot }}(\mathrm{BW})$

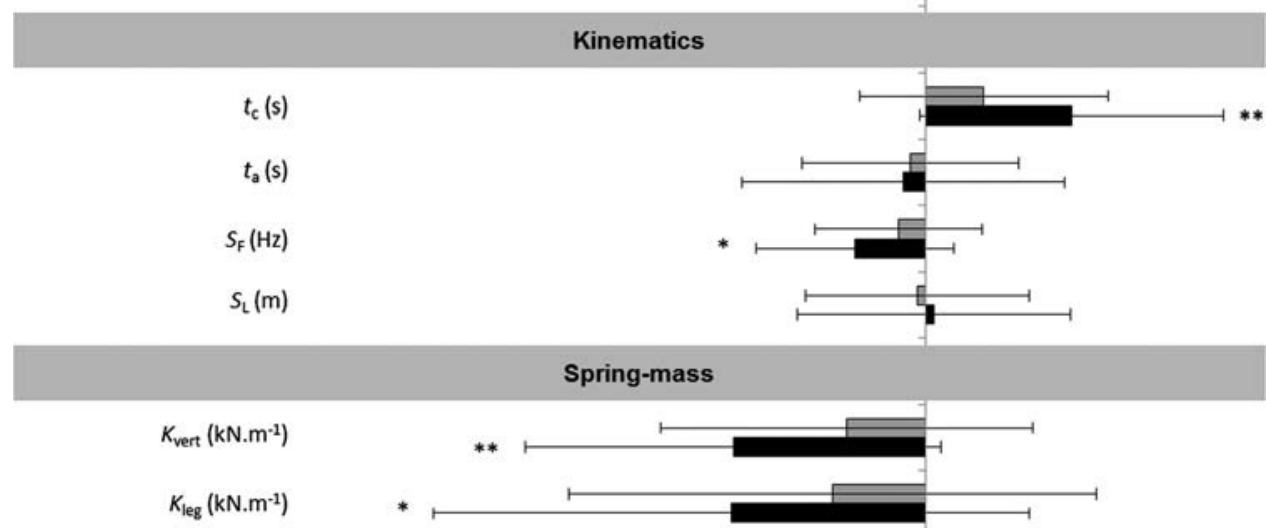

FIGURE 6-Comparison of averaged running mechanical data for the eight sprints in MH and SH in reference to SL. Values are mean \pm SD, $N=13$. Significantly different from SL, $* P<0.05$ and $* * P<0.01$.

extent to which a stiffer musculotendinous system allows for preservation of efficient elastic energy contribution at maximal sprinting with exacerbated fatigue (i.e., SH) (9), thereby maintaining force production during the concentric phase of the movement (9) needs to be ascertained.

Several potential limitations deserve attention. First, using step changes in $\mathrm{FiO}_{2}$ as hypoxic stimulus is associated with larger interindividual variability in the degree of arterial hypoxemia (and related stimulus at the muscle level) as opposed to predetermined values of $\mathrm{SpO}_{2}$ (8). That said, whether clamping $\mathrm{SpO}_{2}$ will cause better heterogeneity in the oxygenation response and similar hypoxia-induced neuromechanical alterations compared with the "classic" approach using fixed $\mathrm{FiO}_{2}$ values is unknown. Second, it remains also to be verified whether hypobaric and normobaric hypoxia holds the same potential for alterations in (repeated) sprint performance and shares similar underlying neuromechanical mechanisms (30). Third, with "repeated sprints in hypoxia" undergoing unprecedented popularity, quantifying neuromechanical responses of training sessions that include three to five sets of repeated sprints as performed here with different combinations of exercise-to-rest ratios (36) is needed to appropriately

\section{REFERENCES}

1. Amann M, Romer LM, Subudhi AW, Pegelow DF, Dempsey JA. Severity of arterial hypoxaemia affects the relative contributions of peripheral muscle fatigue to exercise performance in healthy humans. J Physiol. 2007;581(Pt 1):389-403.

2. Balsom PD, Gaitanos GC, Ekblom B, Sjodin B. Reduced oxygen availability during high intensity intermittent exercise impairs performance. Acta Physiol Scand. 1994;152(3):279-85. manage residual fatigue. Last, it may also be warranted to investigate the effect of an increase in muscle activation strategies through kinematic compensation (i.e., joint actions and neuromuscular coordination) arising from team sport specific training (e.g., resistance or repeated sprints in hypoxia) and the effect that this may have during accelerated runs in field conditions.

To conclude, in $\mathrm{SH}\left(\mathrm{FiO}_{2}=13.3 \% ; \sim 3600 \mathrm{~m}\right)$, impairments in RSA and in accompanying kinetics/kinematics and spring-mass characteristics exceed those observed near $\mathrm{SL}\left(\mathrm{FiO}_{2}=20.9 \%\right)$ and in $\mathrm{MH}\left(\mathrm{FiO}_{2}=16.8 \% ; \sim 1800 \mathrm{~m}\right)$. Specifically, $\mathrm{SH}$ accentuates the RSA fatigue-related inability to effectively apply forward-oriented ground reaction force and to maintain vertical stiffness and stride frequency.

This work is based on research funded by QNRF (NPRP 4-760-3-217). The authors gratefully acknowledge the participants for their enthusiasm and collaboration.

The authors declare no conflict of interest and have no financial ties to disclose.

The results of the present study do not constitute endorsement by the American College of Sports Medicine.

3. Billaut F, Buchheit M. Repeated-sprint performance and vastus lateralis oxygenation: effect of limited $\mathrm{O}(2)$ availability. Scand $J$ Med Sci Sports. 2013;23(3):e185-93.

4. Billaut F, Kerris JP, Rodriguez RF, Martin DT, Gore CJ, Bishop DJ. Interaction of central and peripheral factors during repeated sprints at different levels of arterial $\mathrm{O}_{2}$ saturation. PLoS One. 2013; 8(10): 77297 
5. Bowtell JL, Cooke K, Turner R, Mileva KN, Sumners DP. Acute physiological and performance responses to repeated sprints in varying degrees of hypoxia. J Sci Med Sport. 2014;17(4):399-403.

6. Brocherie F, Girard O, Faiss R, Millet GP. High-intensity intermittent training in hypoxia: a double-blinded, placebo-controlled field study in youth football players. J Strength Cond Res. 2015; 29(1):226-37.

7. Brocherie F, Millet GP, Girard O. Neuro-mechanical and metabolic adjustments to the repeated anaerobic sprint test in professional football players. Eur J Appl Physiol. 2015;115(5):891-903.

8. Chapman RF. The individual response to training and competition at altitude. Br J Sports Med. 2013;47(1 Suppl):i40-4.

9. Chelly SM, Denis C. Leg power and hopping stiffness: relationship with sprint running performance. Med Sci Sports Exerc. 2001; 33(2):326-33.

10. Clark KP, Weyand PG. Are running speeds maximized with simplespring stance mechanics? J Appl Physiol (1985). 2014;117(6): 604-15.

11. Dorn TW, Schache AG, Pandy MG. Muscular strategy shift in human running: dependence of running speed on hip and ankle muscle performance. J Exp Biol. 2012;215(Pt 11):1944-56.

12. Farley CT, Blickhan R, Saito J, Taylor CR. Hopping frequency in humans: a test of how springs set stride frequency in bouncing gaits. J Appl Physiol. 1991;71(6):2127-32.

13. Faude O, Koch T, Meyer T. Straight sprinting is the most frequent action in goal situations in professional football. J Sports Sci. 2012; 30(7):625-31.

14. Garvican LA, Hammond K, Varley MC, Gore CJ, Billaut F, Aughey RJ. Lower running performance and exacerbated fatigue in soccer played at $1600 \mathrm{~m}$. Int J Sports Physiol Perform. 2014; 9(3):397-404.

15. Girard O, Amann M, Aughey R, et al. Position statement-altitude training for improving team-sport players' performance: current knowledge and unresolved issues. Br J Sports Med. 2013;47(1 Suppl): i8-16.

16. Girard O, Brocherie F, Morin JB, Degache F, Millet GP. Comparison of four sections for analysing running mechanics alterations during repeated treadmill sprints. J Appl Biomech. 2015;31(5); 389-95.

17. Girard O, Brocherie F, Morin JB, Millet GP. Intrasession and intersession reliability of running mechanics during treadmill sprints. Int J Sports Physiol Perform. 2016;11(4):432-9.

18. Girard O, Brocherie F, Morin JB, Millet GP. Neuro-mechanical determinants of repeated treadmill sprints - usefulness of an "hypoxic to normoxic recovery" approach. Front Physiol. 2015;6:260.

19. Girard O, Mendez-Villanueva A, Bishop D. Repeated-sprint ability - part I: factors contributing to fatigue. Sports Med. 2011; 41(8):673-94.

20. Girard O, Micallef JP, Millet GP. Changes in spring-mass model characteristics during repeated running sprints. Eur J Appl Physiol. 2011;111(1):125-34.

21. Girard O, Racinais S, Kelly L, Millet GP, Brocherie F. Repeated sprinting on natural grass impairs vertical stiffness but does not alter plantar loading in soccer players. Eur J Appl Physiol. 2011; 111(10):2547-55.

22. Goodall S, Charlton K, Howatson G, Thomas K. Neuromuscular fatigability during repeated-sprint exercise in male athletes. Med Sci Sports Exerc. 2015;47(3):528-36.

23. Goods PS, Dawson BT, Landers GJ, Gore CJ, Peeling P. Effect of different simulated altitudes on repeat-sprint performance in teamsport athletes. Int J Sports Physiol Perform. 2014;9(5):857-62.
24. Hogan MC, Richardson RS, Haseler LJ. Human muscle performance and $\mathrm{PCr}$ hydrolysis with varied inspired oxygen fractions: a 31P-MRS study. J Appl Physiol. 1999;86(4):1367-73.

25. Hunter JP, Marshall RN, McNair PJ. Interaction of step length and step rate during sprint running. Med Sci Sports Exerc. 2004;36(2): 261-71.

26. Hureau TJ, Olivier N, Millet GY, Meste O, Blain GM. Exercise performance is regulated during repeated sprints to limit the development of peripheral fatigue beyond a critical threshold. Exp Physiol. 2014;99(7):951-63.

27. Kawamori N, Nosaka K, Newton RU. Relationships between ground reaction impulse and sprint acceleration performance in team sport athletes. J Strength Cond Res. 2013;27(3):568-73.

28. Kon M, Nakagaki K, Ebi Y, Nishiyama T, Russell AP. Hormonal and metabolic responses to repeated cycling sprints under different hypoxic conditions. Growth Horm IGF Res. 2015;25(3):121-6.

29. Kuitunen S, Komi PV, Kyrolainen H. Knee and ankle joint stiffness in sprint running. Med Sci Sports Exerc. 2002;34(1):166-73.

30. Millet GP, Faiss R, Pialoux V. Point: hypobaric hypoxia induces different physiological responses from normobaric hypoxia. $J$ Appl Physiol. 2012;112(10):1783-4

31. Mollard P, Woorons X, Letournel M, et al. Determinants of maximal oxygen uptake in moderate acute hypoxia in endurance athletes. Eur J Appl Physiol. 2007;100(6):663-73

32. Morin JB, Bourdin M, Edouard P, Peyrot N, Samozino P, Lacour JR. Mechanical determinants of $100-\mathrm{m}$ sprint running performance. Eur J Appl Physiol. 2012;112(11):3921-30.

33. Morin JB, Dalleau G, Kyrolainen H, Jeannin T, Belli A. A simple method for measuring stiffness during running. $J$ Appl Biomech. 2005;21(2):167-80.

34. Morin JB, Edouard P, Samozino P. Technical ability of force application as a determinant factor of sprint performance. Med Sci Sports Exerc. 2011;43(9):1680-8.

35. Morin JB, Samozino P, Bonnefoy R, Edouard P, Belli A. Direct measurement of power during one single sprint on treadmill. $J$ Biomech. 2010;43(10):1970-5.

36. Morin JB, Samozino P, Edouard P, Tomazin K. Effect of fatigue on force production and force application technique during repeated sprints. $J$ Biomech. 2011;44(15):2719-23.

37. Morin JB, Slawinski J, Dorel S, et al. Acceleration capability in elite sprinters and ground impulse: push more, brake less? J Biomech. 2015;48(12):3149-54.

38. Morrison JD, Lovell D, McLellan C, Minahan C. Performance and metabolic responses of highly-trained team-sport athletes during repeated sprinting in hypoxia. $J$ Athl Enhanc. 2015;4(2):1-5.

39. Nagahara R, Matsubayashi T, Matsuo A, Zushi K. Kinematics of transition during human accelerated sprinting. Biol Open. 2014;3(8): 689-99.

40. Nassis GP. Effect of altitude on football performance: analysis of the 2010 FIFA World Cup Data. J Strength Cond Res. 2012;27(3): 703-7.

41. Rabita G, Dorel S, Slawinski J, et al. Sprint mechanics in worldclass athletes: a new insight into the limits of human locomotion. Scand J Med Sci Sports. 2015;25(5):583-94.

42. Schache AG, Dorn TW, Williams GP, Brown NA, Pandy MG. Lower-limb muscular strategies for increasing running speed. J Orthop Sports Phys Ther. 2014;44(10):813-24.

43. Weyand PG, Lee CS, Martinez-Ruiz R, Bundle MW, Bellizzi MJ, Wright S. High-speed running performance is largely unaffected by hypoxic reductions in aerobic power. J Appl Physiol (1985). 1999;86(6):2059-64. 